\title{
Examining student nurses' perceptions of diverse populations: Are student nurses prepared to care for culturally diverse patients?
}

\author{
Mary J o C Stanley ${ }^{1}$, J anice Hayes ${ }^{2}$, Fredrick L. (Rick) Silverman ${ }^{3}$ \\ 1. University of Colorado at Colorado Springs, Colorado Springs, USA. 2. School of Nursing, College of Natural and Health \\ Sciences, University of Northern Colorado, Greeley, USA. 3. School of Teacher Education, College of Education and \\ Behavioral Sciences, University of Northern Colorado, Greeley, USA.
}

Correspondence: Mary Jo C Stanley. Address: University of Colorado at Colorado Springs, Colorado Springs, USA. Email: mstanley@uccs.edu

Received: March 6, 2014

Accepted: April 22, $2014 \quad$ Online Published: May 19, 2014

DOI : $10.5430 /$ jnep.v4n7p148

URL: http://dx.doi.org/10.5430/jnep.v4n7p148

\section{Abstract}

Background/Objectives: The purpose of this study is to examine student nurses' perceptions of diverse population, as experienced through their clinical environments in nursing school. Student nurses will encounter diverse populations in practice; nursing education must critically address how students are being prepared to care for diverse populations and the strategies that assist students to be successful in caring for those with different values and beliefs than themselves.

Methods: Denzin's Interpretive Interactionism was used to elicit meaning from eight senior level nursing students from a baccalaureate nursing program.

Results: Commonality in students' stories was expressed through their experiences where three themes emerged: unprepared for cultural diversity, care should be personalized, and moral challenges.

Conclusion: Responses from students in this study indicate that their acquisition of knowledge was not sufficient to engender understanding of the network of concepts inherent in cultural diversity. Stories indicate classroom and clinical experiences were not sufficient for student nurses to care for diverse populations with confidence in their abilities.

\section{Key words}

Cultural diversity, Diverse populations, Cultural competence, Nursing education

\section{Introduction and background}

Increasing cultural diversity within the United States necessitates preparing nursing students to be culturally conscious in the care they provide to patients, families, and populations. Current demographics show that over one-third of the population reports their race and ethnicity as something other than non-Hispanic White ${ }^{[1]}$. To prepare nurses for this challenge, schools of nursing must provide foundations for students to learn to effectively provide this care. The American Association of Colleges of Nursing Advisory Committee states that curriculum has not addressed the necessary skills for nursing students to provide culturally competent care, "Existing curriculum models often fall short of the needs of nurses who encounter diverse patients in their clinical or practicum areas, and more is needed to prepare them with the knowledge, attitudes, and skills of cultural competence" ${ }^{[2]}$. While cultural content may be included in baccalaureate programs, 
variability in depth and breadth of content might vary ${ }^{[3]}$. The American Association of Colleges of Nursing ${ }^{[4]}$ has called for greater understanding and respect related to populations culturally and ethnically diverse from dominant society. Giger et al. ${ }^{[5]}$ defines diversity as: “...race, color, ethnicity, national origin, religion, age, gender, sexual orientation, ability/disability, social and economic status or class, education, occupation, religious orientation, marital and parental status, and other related attributes of groups of people in society”. Student nurses will encounter diverse populations in practice; nursing education must critically address how students are being prepared to care for diverse populations and the strategies that assist students to be successful in caring for those with different values and beliefs than themselves.

Immigration and a changing global world have contributed to cultural diversity within the United States presenting unique challenges to healthcare providers. Cultural practices are foundational for many populations; when patients are pressured to relinquish their cultural beliefs, anger, mistrust, and resentment may result ${ }^{[7]}$. Provider regard for cultural practices and beliefs is essential; yet, discrepancies exist in provider and patient perceptions of cultural competency. The United States Department of Health and Human Services ${ }^{[6]}$ identifies culture as “....integrated patterns of human behavior that include the language, thoughts, communications, actions, customs, beliefs, values, and institutions of racial, ethnic, religious, or social groups. 'Competence' implies having the capacity to function effectively as an individual and an organization within the context of the cultural beliefs, behaviors, and needs presented by consumers and their communities”.

Shapiro, Hollingshead, and Morrison's ${ }^{[8]}$ qualitative design identified differences among physician-residents, faculty, and patients regarding culturally appropriate care. Physician-residents and faculty focused on cultural knowledge and communication, while patients emphasized the importance of people skills and patient treatment. Anderson's ${ }^{\text {[9] }}$ quantitative study surveyed 45 undergraduate nursing students and found that prior to a cultural education project students believed they were already culturally competent. Initially, nursing student responses to prescribed scenarios prompted an assessment of noncompliance without consideration of cultural preferences for the Mexican-American patient and family. While students acknowledged greater self-awareness after the project, they seemed unable to fully change their perceptions stating a preference for their own values and a belief in Western medicine. In another study, Hunter's ${ }^{[10]}$ integration of cultural material into a nursing graduate class to increase cultural awareness showed that students in this course had limited understanding of diverse cultures; many of the students had not been exposed to diverse populations nor had they traveled outside of the United States. Student naivety presented as ethnocentric comments and apathy toward diverse populations. Understanding cultural differences includes recognizing the societal, economic, and political concerns that influence patients and their healthcare choices.

The purpose of this research study is to examine student nurses' perceptions of diverse population, as experienced through their clinical environments in nursing school. The research question is: What are senior level undergraduate nursing students' perceptions related to diversity as experienced through their clinical environments in nursing school? Literature supports the need for increased cultural competence in the healthcare setting, yet inclusion of cultural content in nursing curriculum has not assured cultural understanding and an appreciation for cultural differences. Inquiry into students' perception of the meaning of culture and caring for diverse populations might provide insight for future educational practices.

\section{Methodology}

Denzin's ${ }^{[11]}$ Interpretive Interactionism was used to educe meaning from nursing students in a baccalaureate nursing program in the Rocky Mountain region of the United States. Interpretive Interactionism is both a method and perspective as it draws on aspects of social theory where elements such as power, emotion, and history may be revealed ${ }^{[9]}$. Interpretive interactionism looks at social situations and the interactive process. Personal stories are collected from those who share commonality with the phenomenon of interest. Through thick description, stories emerge and illuminate epiphanies or turning points in the person's experience. 
Thirty five accessible senior level student nurses were invited to participate in the study. From this cohort, a convenience sample of twelve students agreed to participate; eight students completed the study. Nursing students currently in their senior preceptorship experience, and completing their final 225 clinical hours met inclusion criteria. Students who would be completing their final semester of nursing school have been exposed to a variety of clinical environments (medical/surgical, maternal, psychiatric, pediatrics, and community health) and could best share their story related to diversity from their undergraduate clinical settings. The eight nursing students completing the study were 21 years of age and older and agreed to participate through signed consent. Institutional Review Board approval was obtained for this study.

Reflective narratives were collected from the participants. Two journals were collected --one during the first half and one during the second half of their 225 hour clinical preceptorship experience. These journals provided reflection on students' current clinical experiences and were in addition to required coursework; no grade was associated with the journals or participation in the study. Nursing students used Asselin's ${ }^{[12]}$ journal writing guide to direct their reflective journaling. Interviews were also conducted at the completion of student's final 225 clinical hours. The interview questions lasted 20-30 minutes. The interview questions were open-ended and were audio-recorded. Students' responded to the question, “Tell me about working with diverse individuals/populations and what this means to you?” All audio-recorded data was transcribed, verbatim.

Interview and journal data were aggregated and coded for each participant. Fictitious names were then assigned to the participants. Narratives were analyzed following Denzin's ${ }^{[11]}$ procedural steps: (a) Bracketing- key phrases, epiphanies or statements essential to the element under investigation were isolated. Bracketing was done through full immersion in the data; all eight participants' transcripts and journals were read and re-read. Key phrases and statements from the narratives were identified and coded. Analysis meetings with members of the dissertation committee ensured agreement on coding and identification of ten categories from the narrative data. Transcripts of identified categories were sent to participants to verify meaning of content; (b) Construction- parts of the phenomena were brought together; elements of the phenomena were ordered and looked at by how they affect or relate to other elements. The ten categories were compared and sorted; the larger context was considered when condensing and labeling the categories. Discrete categories were subsumed into dominant categories (for example, judgment and personal conflict became moral challenges) and reviewed with the dissertation chair; (c) Contextualization- entails personal stories that embody the phenomena; main themes were compared and synthesized into reformulated statements. Three reoccurring themes embodied the greater meaning of student nurses' experiences. Participant's stories that exemplified the themes were brought together to tell the larger story of students' perceptions related to diversity as experienced through their clinical environments in nursing school. Procedural rigor for the study was followed through prolonged engagement with data, an audit trail, reflective journaling, peer review, and member checking ${ }^{[13]}$.

\section{Results}

Demographic data was collected and aggregated for the eight participants who ranged in age from 21-28. All participants were female and six of the eight participants were white. Six participants had prior experience working in health care and prior experience working with diverse populations.

To answer the research question "What are senior level undergraduate nursing students' perceptions related to diversity as experienced through their clinical environments in nursing school?” data from undergraduate nursing students' journals and transcripts was analyzed. Commonality in their stories was expressed through their experiences where three themes emerged: unprepared for cultural diversity, care should be personalized and moral challenges.

\subsection{Unprepared for cultural diversity}

Student shared that they were unprepared for the complexities associated with caring for culturally diverse patients. One student acknowledged that early in her clinical courses, she was not thinking about diversity and providing culturally 
competent care. Students acknowledged that they focused on the things they knew and were comfortable doing rather than provide for patient's cultural needs; attention was given to the patient's disease. Students stated that they focused on skill sets rather than cultural aspects, and that despite five semesters of nursing training, "seeing the bigger picture" did not come naturally:

"I was so focused on tasks and doing what I was supposed to be doing that it was really hard to look at that side of things...you learn what it is and you might try to apply it but until it really comes to a situation that hits you, I don't think you really think about it and put it together. I think it would have been easier to accept if I had maybe a little more exposure to it in the curriculum. And just dealing with the fact that you know you are going to be taking care of people who are-are different, just totally different. It is just hard to consider the whole picture." (Brittany)

"And I still don't think that we place enough emphasis on it because - not because it is necessarily something that is hard. I think we don't realize how vitally important and necessary it is and when we are getting twenty times more information about diseases--this disease or that disease or diabetes or whatever, it is easy to overlook the things that aren't constantly put in our face and thus I think it is easy to go through nursing school not developing the full cultural competence we could just because it is not always stressed in every moment as much as this person is hypoglycemic or this person is having a heart attack." (Jaclyn)

Students felt that to be better prepared to care for diverse patients, more emphasis on culture in nursing school was necessary. Students felt curriculum should stress inclusion of culture so that it is a part of one's practice, and that typecasting of cultural groups should be avoided. Students felt class assignments did not provide the cultural knowledge they needed and did not prepare them for the situations they would encounter:

"I feel like in every class we had a project about culture. And a lot of what it boiled down to was each group would be a different culture and we would say like well these are the aspects of this culture. And it never really works out that way in real life. People are unique and different so they are not going to fit into these little boxes we try to put them in. So if we learn in class that most Hispanic people are Catholic that doesn't mean if I am working with a Hispanic patient I should expect them to have Catholic beliefs. So it is really hard to not cross the line of just going into stereotypes.” (Mackenzie)

"Through our classes, we had several projects that related to cultural awareness. While it can sometimes be helpful to have a base of knowledge about a culture, I felt as though this did little but to perpetuate stereotypes. For example, in class we, either directly or indirectly, perpetuated the stereotypes that Hispanic families are male-dominated, poor, and eat unhealthily; Somali women are circumcised and do not believe in C-sections or epidurals; and Catholic patients believe suffering is punishment for sins. Through my limited experience with real patients, all of these stereotypes have proven to be false." (Jessa)

Students struggled to incorporate cultural care into their practice and expressed being overwhelmed or lacking educational preparation to assist them in this process. Cultural assignments did not offer students an authentic enough representation of diverse individuals and did not provide the cultural knowledge needed to prepare them for the situations they would encounter in the clinical setting.

\subsection{Care should be personalized}

Students recounted clinical experiences where patients did not follow expected cultural responses. One student stated that as health care providers, we should not make assumptions about care based on a patient's culture; patients will not necessarily follow a textbook response. Students acknowledged that caring for the patient was not about treating the culture but about treating the patient:

“For example, like I had a Hispanic couple that had lost a pregnancy and they didn't want a priest and they didn't want a baptism and they didn't want any of those kinds of things we would think people who follow catholic faith would want. So 
it was just kind of a good lesson in being open to what they want regardless of what we have preconceived ideas about." (Amanda)

Brittany shared a story of a Native American patient who used a medicine man as part of their cultural practice. She acknowledged the importance of this ritual to the well-being of the patient, realizing that diversity included the beliefs and practices unique to each individual:

"I did have a patient once that was Native American and had the medicine man come and practice a ritual in the room and that was very private. And it was important to them that even though she needed these things and nursing tasks taken care of, there was a solid set of four hours where there was nobody there doing anything with her because the medicine man was there." (Brittany)

Rianna's story acknowledged the differences in culture that existed within the Hispanic population. She stated that culture could be diverse even within cultural groups and that care should be individualized:

"What I assumed was that since Guatemala is below Mexico, the countries would be similar in Spanish-speaking....I feel as though I stereotyped my own ethnicity a little by assuming that the Spanish spoken would be mostly the same. The main point I should know is that everyone is different, and care needs to be individualized even if you come from similar cultures.” (Rianna)

Students expressed the need to individualize patient care and not typecast a patient based on their identified culture. In addition, students showed openness to the beliefs and practices of others, identifying that assumptions and stereotypes did not assist in providing good care in the clinical setting.

\subsection{Moral challenges}

Students' shared stories of difficult situations and the challenge to balance professional roles with personal values. Prescribed male/female roles, Western society viewpoints, differences in cultural and religious beliefs, and disrespectful behaviors toward those diverse presented challenges for students:

"One story that definitely stands out as trying for me and a huge learning experience in culture competence would have been during my rotation dealing with a particular woman who was first of all married and was 13 and was pregnant with her second child, obviously all a result of the culture beliefs of that culture. Crazily different than my own. And furthermore dealing with the fact that she was fully circumcised and stitched up and now pregnant and in impending labor. I think one of the biggest challenges I had to consciously overcome was I saw this 13-year-old and I almost instinctively just treated her like a child because to me she was one. But she was a woman giving birth who had accomplished more from motherhood and womanhood standpoint than I had even begun to think about in my own life." (Jaclyn)

Summer shared her story of caring for an individual with strong religious beliefs. She struggled with her religious convictions and grappled with the nurse's role in providing care that incorporated moral and cultural values different from her own.

"I took care of a Jehovah's Witness and she had just gotten back from surgery and she had a lot of blood loss. And they don't do the human blood products and I was born and raised Catholic. It's kind of--that's kind of hard. I don't really want to say my morals were challenged but it was hard to see someone die because of they didn't want to receive the blood products. Because at the same time it was my religion that made me believe there is life after and there are greater things after you die and everything. Kind of differentiating the nursing care side and then the religious belief side and kind of finding a balance between that." (Summer) 
Situations where patients were judged were shared through student's stories. During her rotation with a community agency, Keily witnessed a nurse judging the patient's compliance based on their ethnicity. Kiely expressed her concern with this situation as she was taught to care for all patients, yet witnessed less than caring behaviors.

"When I was at the (name of agency) we worked with a lady who was kind of in charge of tuberculosis all over the county. And of course different backgrounds and everybody gets it (receive medication), but she'd say some certain ethnic backgrounds they would get it (receive medication) and then they wouldn't be compliant, but you can't just judge that a background won't be compliant just because of that. You need to, you know, everybody has to make their own choice and so you just need to give them their medications and tell them the treatment and that it is going to be beneficial to them. And just provide them with all the education you can and then they will make their own decision. You can't just decide by looking at someone if they are going to take their meds or not." (Kiely)

Students shared stories of morally conflicting situations where values differed and preconceptions toward those culturally diverse were expressed. As novice nurses, students might have limited clinical and/or life experience to respond to these challenges and were conflicted with what was the morally right action.

\section{Limitations}

Limitations for this study include students' stories as told from eight female students in a baccalaureate nursing program and inclusion of only nursing students at the undergraduate level in their final clinical semester. In addition, faculty perspectives were not included in this study.

\section{Discussion}

The research question "What are senior level undergraduate nursing students' perceptions related to diversity as experienced through their clinical environments in nursing school?” prompted responses from students that indicate their acquisition of knowledge, which is necessary, was not sufficient to engender understanding of the network of concepts inherent in cultural diversity. Similar to the literature, students' grappled with issues related to diversity and cultural competence $^{[9,14-19]}$. Stories indicate classroom and clinical experiences were not sufficient for student nurses to care for diverse populations with confidence in their abilities.

Students' expressed difficulty in incorporating cultural care into their practice, stating a lack of educational preparedness to address the cultural needs of their patients. Much like the results from this study, Reeves and Fogg's ${ }^{[18]}$ study acknowledged students' feelings of being unprepared in providing culturally competent care after graduation. Kennedy et $a l .{ }^{[16]}$ raised concern that schools of nursing are reinforcing dominant cultural practices, perpetuating students' feelings of unpreparedness when working with diverse populations. Application, understanding, and appreciation for the cultural context may better assist students in the clinical environment than cultural facts alone; Hawaala-Druy and Hill ${ }^{[20]}$ propose a holistic approach to nursing education that “...would address all phases of developing cultural conscious attitudes and care beyond basic fact memorization....and interactive and inter-professional exercises that allow students to practice applying learned knowledge....”. Cultural specific information has not provided students with sufficient knowledge for them to develop an appreciation for cultural differences. Educators must be willing to adapt their teaching strategies applying an active approach for contextual understanding. This area warrants further examination as we prepare students to care for a diverse patient population.

Students discussed the need to address individual patient preferences where care should be personalized. Assessment of the individual could dissolve cultural typecasts, allowing care to be provided without stereotypes or prejudged assumptions. Students recounted clinical experiences where patients did not follow expected cultural or textbook response acknowledging that identified cultures might stray from typical cultural expectations. Students acknowledged that caring 
for the patient was not about treating the identified culture, but about treating the patient. Beach et al. ${ }^{[21]}$ posits that knowledge-based cultural information might encourage patient stereotypes, promoting the belief that all members of a cultural group are similar. To avoid cultural labels, nurse educators should focus instruction on treating the patient, not the identified culture, but not the patient as devoid of culture.

Student's shared stories related to moral challenges in caring for culturally diverse patients. Students' experienced situations in which their moral values were in some way disconsonant with their professional roles within the clinical setting. The results of this study were much like those of Anderson ${ }^{[9]}$ who revealed ethnocentric beliefs in student nurses and assumptions regarding the superiority of Western medicine when caring for diverse individuals. Nurses might not realize they hold these prejudices, presenting unwitting bias in the care they provide. Lipson and Desantis ${ }^{[17]}$ state: "Homogenous student populations rarely encounter patients who challenge their work views and social norms. Without such challenges, students often see culture as something out there, irrelevant, and not affecting their practice. They tend to judge their patients’ beliefs and practices from their own perception of reality.”

Students grapple with morally challenging situations; as novice nurses, they have limited exposure and training to deal with these issues. Kennedy et al. ${ }^{[16]}$ posits that nurse educators should spend less time focusing on cultural content knowledge and, instead, promote cultural humility. Sanner et al. ${ }^{[19]}$ supports discussion of racial and ethnic issues in the classroom; frequency of dialogue surrounding such issues creates awareness toward social injustices.

Traditional methods of education have not mitigated bias or stereotypes toward culturally diverse patients; new ways of teaching that emphasize understanding and respectful behaviors for diverse populations must be developed ${ }^{[2]}$. Attention must be given as to how schools of nursing integrate cultural sensitivity and the moral/ethical issues that surround diverse groups. Use of critical social theory (CST) can assist students and educators in reflecting on morally challenging situations, providing greater awareness of one's values and beliefs. CST looks at discriminatory actions that place constraints on race, gender, or class as well as the relationship of power and inequities in structures of society ${ }^{[22]}$. Inclusion of CST as a teaching construct may have value in nursing education. Efforts to address care for culturally diverse populations may require a new approach in cultural education strategies that focus attention on moral and ethical dilemmas. Limited literature exists that examines student nurses' distress related to caring for diverse groups and warrants further examination.

\section{Conclusion}

There is a need to prepare nursing students to provide care to increasingly diverse populations. As both student nurses and patients bring their own world views to the healthcare setting, differences in beliefs become evident and may clash. The concept of diversity is necessary as student nurses struggle with care that incorporates beliefs and values of the patient. Treating each patient as an individual incorporates personalized care; assessment of patient needs without assuming stereotypes can assist students to become better care providers in the healthcare setting. Nursing education must move away from cultural facts and reinforce experiences that support application and an appreciation for culture. Student stories from this study indicate that current practices do not prepare students to care for culturally diverse patients; nursing education must take a judicious look at how culture and diversity is being taught and the teaching practices that support contextual understanding. Inclusion of social justice and teaching strategies informed by CST has value in sensitizing students to discriminatory practices that may be prevalent with diverse populations.

\section{Acknowledgement}

To my dissertation team: Janice Hayes, Ph.D, RN, Fredrick L. (Rick) Silverman, Ed.D, Catherine Dingley, Ph.D, RN, and Jean Giddens, Ph.D, RN; thank you for your guidance and support. 


\section{References}

[1] U.S. Census Bureau. 2010 Census Shows America’s Diversity. 2011. Available from:

http://www.census.gov/newsroom/releases/archives/2010_census/cb11-cn125.html

[2] Calvillo, E., Clark, L., Ballantyne, J., Pacquiao, D., Purnell, L., \& Villarreal, A. Cultural competency in baccalaureate nursing education. Journal of Transcultural Nursing. 2009; 20(2): 137-145. PMid:19129519 http://dx.doi.org/10.1177/1043659608330354

[3] Bentley, R., \& Ellison, K. Increasing cultural competence in nursing through international service-learning experiences. Nurse Educator. 2007; 32(5): 207-211. PMid:17828021 http://dx.doi.org/10.1097/01.NNE.0000289385.14007.b4

[4] American Association of Colleges of Nursing (AACN). Cultural Competency in Baccalaureate Nursing Education. 2008a. Available from: http://www.aacn.nche.edu/leading-initiatives/education-resources/competency.pdf

[5] Giger, J., Davidhizar, R., Purnell, L., Harden, J., Philips, J., \& Strickland, O. American academy of nursing expert panel report: Developing cultural competence to eliminate health disparities in ethnic minorities and other vulnerable populations. Journal of Transcultural Nursing. 2007; 18(2): 95-102. PMid:17416710 http://dx.doi.org/10.1177/1043659606298618

[6] United States Department of Health and Human Services. Office of Minority Health. What is cultural competency. 2014. Available from: http://minorityhealth.hhs.gov/templates/browse.aspx?lvl=2\&lvlID=11

[7] Purnell, L. D., \& Paulanka, B. J. Transcultural health care: A culturally competent approach. Philadelphia, PA: F.A. Davis. 1998.

[8] Shapiro, J., Hollingshead, J., \& Morrison, E. H. Primary care resident, faculty and patient views of barriers to cultural competence, and the skills needed to overcome them. Medical Education. 2002; 36: 749-759. PMid:12191058

http://dx.doi.org/10.1046/j.1365-2923.2002.01270.x

[9] Anderson, K. Teaching cultural competence using an exemplar from literary journalism. Journal of Nursing Education. 2004; 43(6): 253-259. PMid:15230304

[10] Hunter, J. Applying constructivism to nursing education in cultural competence: A course that bears repeating. Journal for Transcultural Nursing. 2008; 19(4): 354-362. PMid:18667629 http://dx.doi.org/10.1177/1043659608322421

[11] Denzin, N. K. Interpretive interactionism, (2nd Ed.). Thousand Oaks, CA: Sage. 2001. PMid:11381132

[12] Asselin, M. Using reflection strategies to link course knowledge to clinical practice: The RN-to-BSN student experience. Journal of Nursing Education. 2011; 50(3): 125-133. PMid:21210605 http://dx.doi.org/10.3928/01484834-20101230-08

[13] Lincoln, Y. S., \& Guba, E. G. Naturalistic inquiry. Newbury Park, CA: SAGE Publications, Inc. 1985.

[14] Benkert, R., Templin, T., Schim, S. M., Doorenbos, A., \& Bell, S. E. Testing a multi-group model of culturally competent behaviors among underrepresented nurse practitioners. Research in Nursing \& Health. 2011; 34: 327-341. PMid:21656784 http://dx.doi.org/10.1002/nur.20441

[15] Jirwe, M., Gerrish, K., \& Emami, A. Student nurses' experiences of communication in cross-cultural care encounters. Scandinavian Journal of Caring. 2010; 24(3): 436-444. PMid:20233352 http://dx.doi.org/10.1111/j.1471-6712.2009.00733.x

[16] Kennedy, H. P., Fisher, L., Fontaine, D., \& Martin-Holland, J. Evaluating diversity in nursing education: A mixed methods study. Journal of Transcultural Nursing. 2008; 19(4): 363-370. PMid:18658117 http://dx.doi.org/10.1177/1043659608322500

[17] Lipson, J. G., \& Desantis, L. A. Current approaches to integrating elements of cultural competence in nursing education. Journal of Transcultural Nursing. 2007; supplement 18(1): 10s-20s.

[18] Reeves, J. S., \& Fogg, C. Perceptions of graduating nursing students regarding life experiences that promote culturally competent care. Journal of Transcultural Nursing. 2006; 17: 171-178. PMid:16595405 http://dx.doi.org/10.1177/1043659605285410

[19] Sanner, S., Baldwin, D., Cannella, K., Charles, J., \& Parker, L. The impact of cultural diversity forum on students’ openness to diversity. Journal of Cultural Diversity. 2010; 17(2): 56-61. PMid:20586367

[20] Hawala-Druy, S. and Hill, M. Interdisciplinary: Cultural competence and culturally congruent education for millennials in health profession. Nurse Education Today. 2012; 32(7): 772-778. PMid:22677114 http://dx.doi.org/10.1016/j.nedt.2012.05.002

[21] Beach, M. C., Price, E. G., Gary, T. L., Robinson, K. A., Gozu, A., Palacio, et al. Cultural competence: A systematic review of health care provider educational interventions. Medical Care. 2005; 43(4): 356-373. PMid:15778639 http://dx.doi.org/10.1097/01.mlr.0000156861.58905.96

[22] Creswell, J. Qualitative inquiry and research design: Choosing among five approaches (2nd ed.). Thousand Oaks, CA: SAGE Publications, Inc. 2007. 